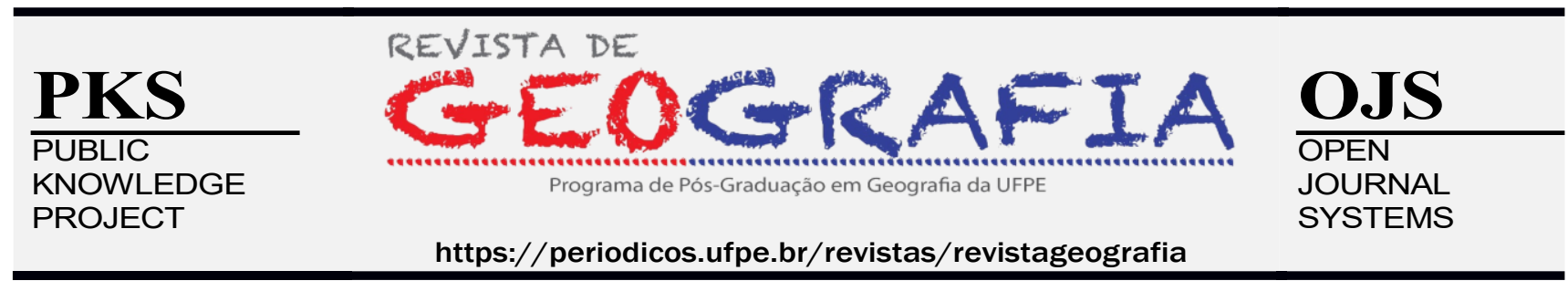

\title{
RELEVO RUINIFORME NO MUNICÍPIO DE CASTELO DO PIAUÍ, PIAUÍ, BRASIL: CARACTERÍSTICAS, POTENCIALIDADES E VALORES
}

\author{
Helena Vanessa Maria da Silva ${ }^{1}$, Claudia Maria Sabóia de Aquino $^{2}$, Renê Pedro de Aquino ${ }^{3}$
}

\author{
'Doutoranda em Geografia, Universidade Federal do Ceará, E-mail: helenavessal8@gmail.com, Orcid: \\ https://orcid.org/0000-0001-9086-2808 \\ 2Professora Dra. do Departamento de Geografia, Universidade Federal do Piauí, E-mail: cmsaboia@gmail.com, Orcid: \\ https://orcid.org/0000-0002-3350-7452 \\ ${ }^{3}$ Professor Me. do Departamento de Geografia, Universidade Estadual do Piauí, E-mail: rene.uespi@hotmail.com, \\ Orcid: https://orcid.org/0000-0003-4142-6764
}

Artigo recebido em 13/07/2021 e aceito em 04/10/2021

\begin{abstract}
RESUMO
A geomorfologia é o ramo das Ciências da Terra preocupada em discutir as formas do relevo e os processos relacionados. Nesse contexto, os relevos do tipo ruiniformes, originados pela erosão pronunciada das rochas, são chamados de paisagens de exceção devido à complexidade de elementos necessários para a sua formação. No Brasil, tais feições podem ser visualizadas, por exemplo, nos complexos de Vila Velha, no Estado do Paraná, e Sete Cidades, no Piauí, locais estudados e/ou apropriados por prática turística. O presente artigo tem como objetivo tratar sobre feições ruiniformes existentes no município de Castelo do Piauí, nas comunidades Baixa do Cajueiro e Pico dos André, Centro-Norte do Estado do Piauí, enfatizando suas características, potencialidades e valores. Os locais são dotados de grande beleza cênica fazendo parte de roteiros turísticos. Recebendo destaque pela exuberância e singularidade, as quais estão diretamente relacionadas aos aspectos geomorfológicos essas paisagens configuram o principal objeto da atração geoturística do munícipio estudado. Conclui-se diante das características, das potencialidades e valores observados nesses locais que o planejamento turístico adequado pode subsidiar a definição de ações, como a criação de roteiros, esquemas de interpretação do patrimônio natural e projetos de educação ambiental.
\end{abstract}

Palavras-chave: Geomorfologia; Relevo ruiniforme; Castelo do Piauí. 


\title{
RUINIFORM RELIEF IN THE MUNICIPALITY OF CASTELO DO PIAUÍ, PIAUÍ, BRAZIL: CHARACTERISTICS, POTENTIALITIES AND VALUES
}

\begin{abstract}
Geomorphology is the branch of Earth Sciences concerned with discussing relief forms and related processes. In this context, the ruiniform reliefs, originated by the pronounced erosion of the rocks, are called exceptional landscapes due to the complexity of the elements necessary for their formation. In Brazil, such features can be seen, for example, in the complexes of Vila Velha, in the State of Paraná, and Sete Cidades, in Piauí, places studied and/or appropriated by tourist practice. This article aims to deal with ruiniform features existing in the municipality of Castelo do Piauí, in the communities Baixa do Cajueiro and Pico dos André, Center-North of the State do Piauí, emphasizing their characteristics, potentialities and values. The places are endowed with great scenic beauty as part of tourist itineraries. Receiving prominence for their exuberance and uniqueness, which are directly related to geomorphological aspects, these landscapes are the main object of geotourism attraction in the studied municipality. It is concluded, given the characteristics, potentials and values observed in these places, that adequate tourism planning can support the definition of actions, such as the creation of itineraries, interpretation schemes for the natural heritage and environmental education projects.
\end{abstract}

Keywords: Geomorphology; Ruiniform relief; Castelo do Piaui.

\section{INTRODUÇÃO}

Segundo Ab’Saber (1977, p. 2) a “topografia ruiniformes são heranças de processos geológicos e geomorfológicos, mais ou menos complexos, que se enquadram na categoria das paisagens de exceção". Ainda segundo o autor "as topografias ruiniformes do Brasil, em sua grande maioria, estão vinculadas a determinados morros testemunhos areníticos” (AB'SABER, 1977, p. 6).

A gênese das feições é oriunda da erosão diferencial que desintegram as rochas. Estão relacionadas a processos físicos e químicos de degradação da rocha e evidenciam as características estruturais e de fraturamento. Nos arenitos seu desenvolvimento é azonal, ou seja, independe do clima, podendo aparecer em regiões tropicais, temperadas ou frias isto porque a sua origem está ligada às características litológicas das rochas (SUGUIU, 1998).

As feições ruiniformes existentes no município de Castelo do Piauí, nas comunidades Baixa do Cajueiro e Pico dos André, Centro-Norte do Estado do Piauí, são dotados de grande beleza cênica fazendo parte de roteiros turísticos. Recebendo destaque pela exuberância e singularidade esses locais apresentam características, potencialidades e variados valores associados (educativo, cultural, turístico, entre outros). 
Diante disso, o presente artigo tem como objetivo tratar sobre feições ruiniformes existentes no município de Castelo do Piauí, enfatizando suas características, potencialidades e valores.

\section{METODOLOGIA}

Para o desenvolvimento da presente pesquisa adotou-se um percurso metodológico que tem suas etapas descritas a seguir:

Com vistas a alcançar os objetivos propostos e a fim de fornecer subsídios teóricos e investigativos da área de estudo, foi inicialmente efetuada uma revisão bibliográfica, teóricometodológica, em artigos, monografias, dissertações, teses, e livros, impressos e eletrônicos sobre geodiversidade, patrimônio geomorfológico, geomorfossítio e relevo ruiniforme.

Posteriormente, foi feita a coleta de dados secundários em documentos e relatórios técnicos a respeito da área em estudo em órgãos, como, a Companhia de Pesquisa de Recursos Minerais CPRM (www.cprm.gov.br/), e o Instituto Brasileiro de Geografia e Estatística - IBGE (www.ibge.gov.br/), um trabalho de gabinete para a elaboração do material cartográfico.

A pesquisa contou ainda com trabalho e coleta de dados em campo e aplicação das fichas de inventariação com base na metodologia de Oliveira (2015). Nesse sentido a visita à área de estudo foi realizada no dia 06 de Outubro de 2019. Para a checagem de campo foi utilizado um receptor GPS (Global Position System) para coleta de coordenadas. Além disso, foi feita uma observação direta com registros fotográficos.

\section{GEOMORFOLOGIA, RELEVO RUINIFORME E GEOTURISMO}

Dentre os elementos naturais que compõem a paisagem, destacam-se os relacionados à geomorfologia, que constitui, segundo Cunha e Vieira (2002), a base sobre a qual se desenvolve a paisagem, condicionando a cobertura vegetal e muitas atividades humanas, constituindo-se desta forma um elemento estruturante das diversas paisagens.

Mora Filho e Ruas (2008) e Guerra (2006) apontam a importância da geomorfologia para os estudos turísticos, principalmente em áreas com trilhas ecológicas, cachoeiras, corredeiras, entre outras, onde há grande afluxo de turistas; nestes casos, os aspectos geomorfológicos atuam no sentido 
de determinar a capacidade de suporte dessas trilhas, favorecendo o desenvolvimento das atividades turísticas de maneira sustentável.

Os estudos que relacionam a geomorfologia e turismo permeiam diversas práticas turísticas. Neste sentido, Cunha e Vieira (2002, p. 9), analisando a prática turística em áreas de montanhas cársticas e graníticas em território português, explicam que,

os elementos geomorfológicos [...] constituem palcos de excepcional beleza, dotados de características ímpares para o desenvolvimento de diferentes atividades de lazer e de recreio ao ar livre e, particularmente, de atividades desportivas relacionadas com a fruição destes espaços naturais e com os desafios que eles colocam.

Como um dos componentes do meio natural, as feições geomorfológicas constituem-se como importantes elementos para o desenvolvimento das atividades humanas, servindo-lhes como locus de ocupação, bem como proporcionando recursos para o crescimento de determinadas atividades econômicas, como o turismo.

Meira e Santos (2014) estudaram os relevos ruiniformes na Serra dos Tapuios, oeste da Bahia. Para estes autores o relevo ruiniforme é oriundo da erosão diferencial em arenito com discordância textural. Hardt e Pinto (2009) e Melo et al. (2002) estudaram o potencial de desenvolvimento de formas de relevo cárstico em quartzitos e arenitos na Chapada Diamantina, estado da Bahia. Silva (2017) estudou as Cidades de Pedras (Microrregião de Picos, Piauí), a chamada Capadócia Nordestina, e no município de Juazeiro do Piauí destaca-se o trabalho de Silva (2020).

Com base na espetacularidade e potencialidades, principalmente do ponto de vista turístico, é fundamental o desenvolvimento de ações relacionadas ao geopatrimônio, notadamente no que se refere ao inventário de locais de interesse geomorfológicos com características excepcionais, aqui entendido de forma ampla como geomorfossítios. O inventário de geomorfossítios é o ato de tornar conhecido, para o meio acadêmico e demais nichos da sociedade, uma determinada feição abiótica bem delimitada geograficamente.

Nesse sentido, este artigo tem como intuito mostrar, por meio da caracterização dos constituintes abióticos, da descrição dos processos evolutivos e do apontamento das suas potencialidades, que os geomorfossítios Baixa do Cajueiro e Pico dos André se distinguem enquanto registro da história do Planeta Terra, por isso se enquadram no conjunto "geopatrimônio", apresentando raridade e excepcionalidades do ponto de vista científico, didático, cênico, turístico, entre outros (AQUINO; AQUINO, 2020; SILVA et al., 2020). 
Sendo assim, a identificação, caracterizarão e avaliação qualitativa desses locais ergue-se como estímulo ao desenvolvimento do conhecimento cientifico e à conservação da natureza, devendo ser incentivado em diferentes escalas e focos de análise.

\section{ÁREA DE ESTUDO}

O município de Castelo do Piauí localiza-se na microrregião de Campo Maior (Figura 1), mesorregião do Centro-Norte Piauiense. Possui área territorial de $2.378,847 \mathrm{~km}^{2}$ tendo como limites ao o município de Pedro II, ao sul São Miguel do Tapuio, a leste área em litígio Piauí/Ceará, e a oeste Campo Maior, Alto Longá e São João da Serra (AGUIAR; GOMES, 2004).

Figura 1: Localização do município de Castelo do Piauí, Piauí, Brasil.

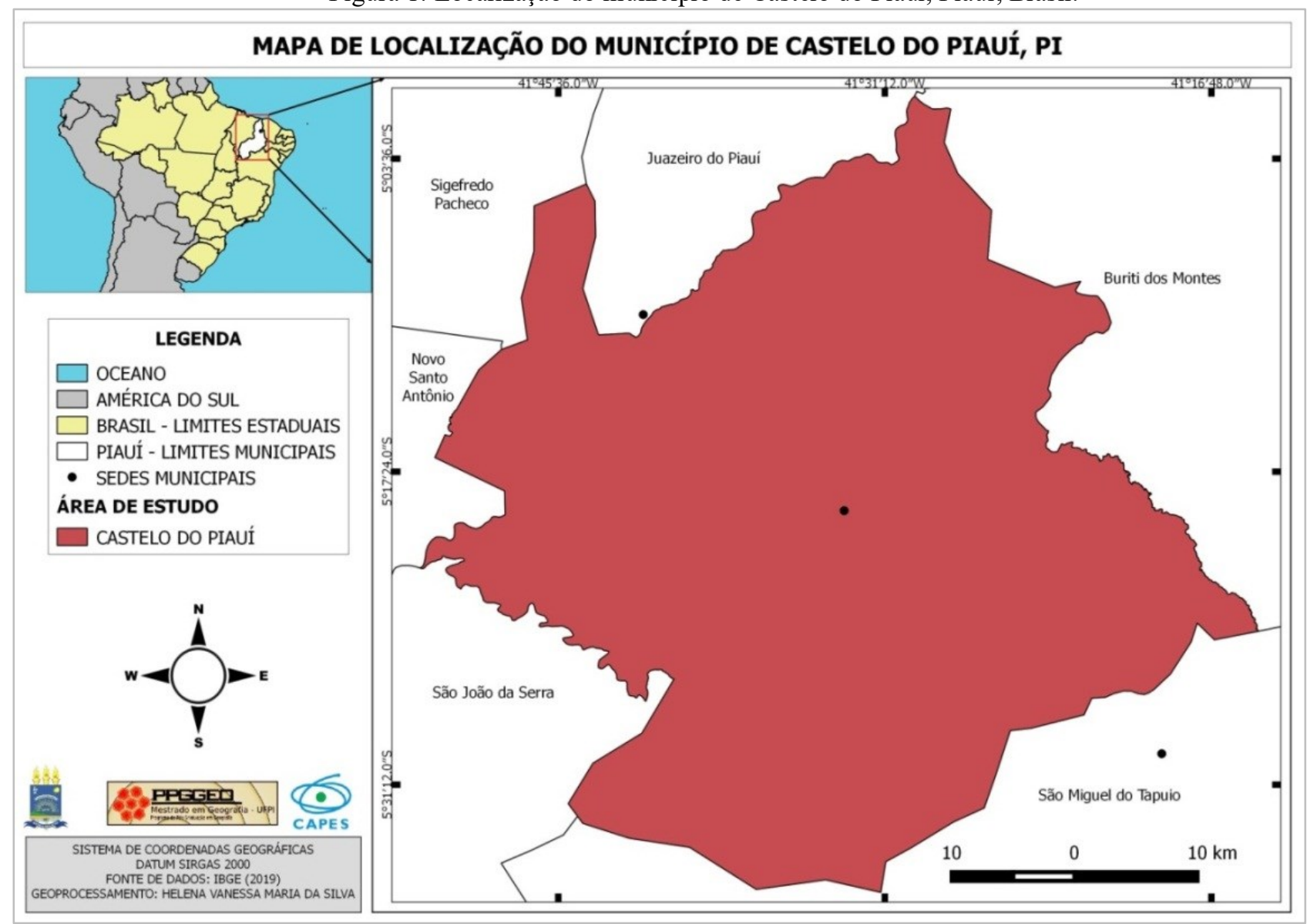

Organização dos autores, 2021.

De acordo com Silva et al. (2020) as unidades geológicas que ocorrem no âmbito do município correspondem às coberturas sedimentares. A Formação Pimenteiras reúne arenito, siltito e folhelho. 
A Formação Cabeças engloba arenito, conglomerado e siltito. Segue-se a Formação Longá compreendendo arenito, siltito, folhelho e calcário. Além destas destacam-se ainda a Formação Sardinha e os Depósitos Colúvio-eluviais, reunindo areia, argila, cascalho e laterito (Figura 2) (AGUIAR; GOMES, 2004).

Figura 2: Esboço geológico do município de Castelo do Piauí/Brasil.

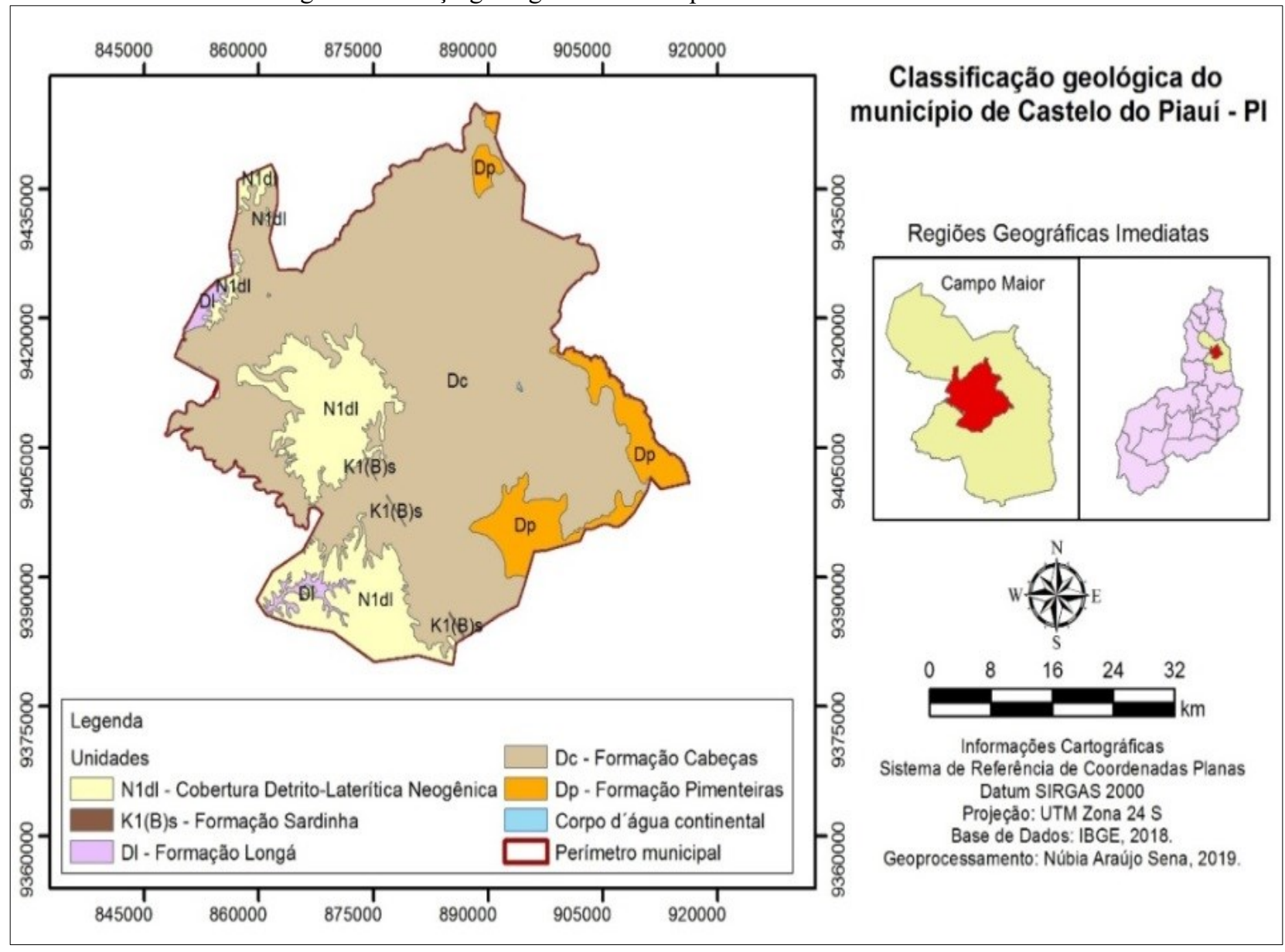

Fonte: Lima, 2019.

Já as feições geomorfológicas da região de acordo com Lima (2019), Aquino e Aquino (2020) e Silva et al. (2020) são resultantes em grande parte dos processos de pediplanação e dissecação (Figura 3). 
Figura 3: Esboço geomorfológico do município de Castelo do Piauí/Brasil.

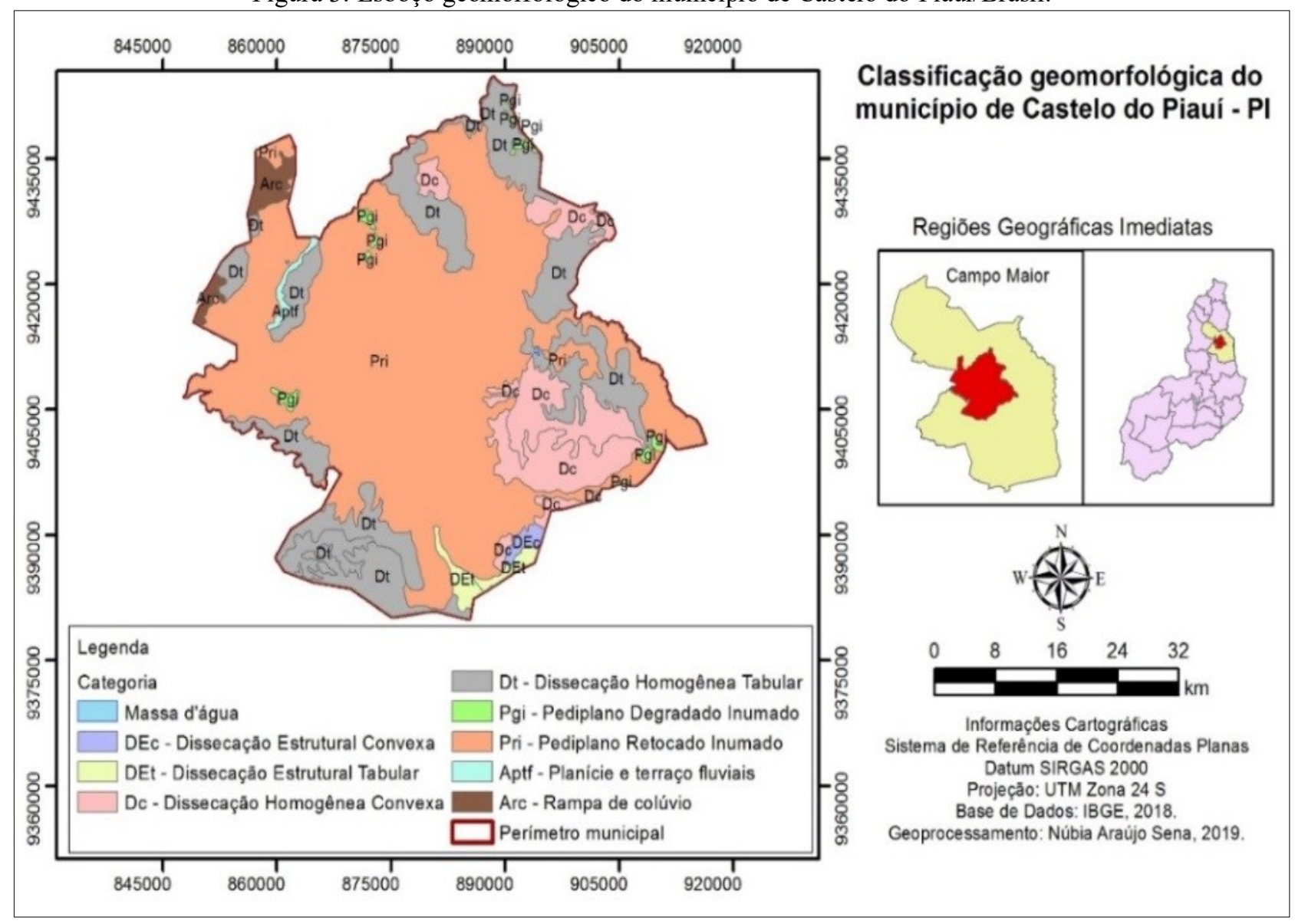

Fonte: Lima, 2019.

Quanto as condições climáticas do município de Castelo do Piauí (com altitude da sede a 239 metros acima do nível do mar) pode-se afirmar que o munícipio apresenta temperaturas mínimas de $23^{\circ} \mathrm{C}$ e máximas de $35^{\circ} \mathrm{C}$ com clima quente tropical. A precipitação pluviométrica média anual é definida no Regime Equatorial Marítimo, com isoietas anuais entre 80 a $1.600 \mathrm{~mm}$, cerca de 5 a 6 meses como os mais chuvosos e período restante do ano de estação seca (JACOMINE, 1983). Os meses de janeiro, fevereiro, março e abril correspondem aos mais chuvosos na região (Figura 4). 
Figura 4: Distribuição da temperatura e da precipitação no município de Castelo do Piauí, Piauí, Brasil.

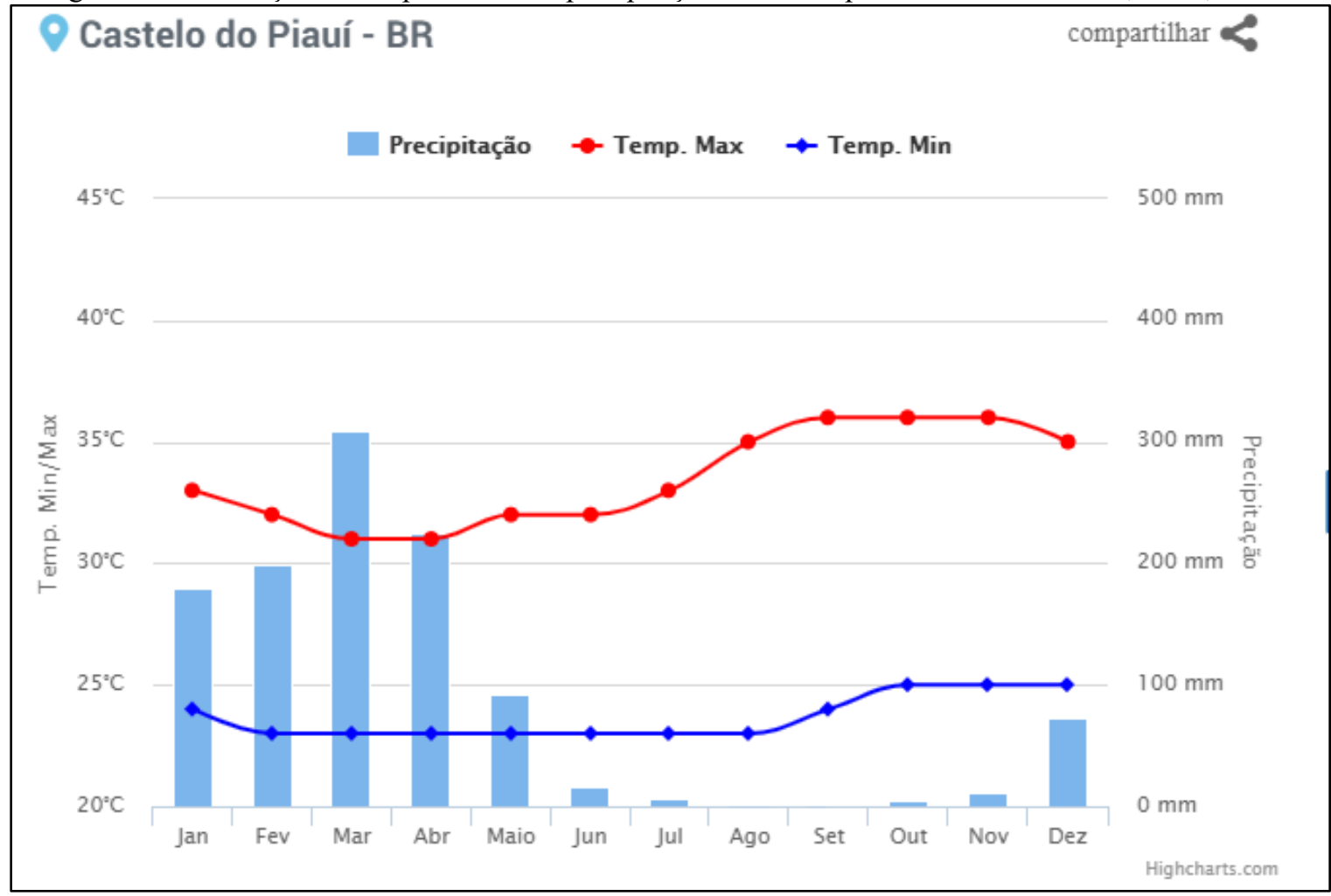

Fonte: https://www.climatempo.com.br/climatologia, 2021.

\section{RESULTADOS E DISCUSSÕES}

\section{LOCAIS DE GRANDE REPRESENTATIVIDADE DE RELEVO DO TIPO RUINIFORME NO} MUNICÍPIO DE CASTELO DO PIAUII, PI, BRASIL

Foram visitados 2 locais de grande representatividade de relevo do tipo ruiniforme no município de Castelo do Piauí, aqui denominados de geomorfossítios, a saber: i) geomorfossítio Complexo Pico dos André e ii) geomorfossítio Baixa do Cajueiro (AQUINO; AQUINO, 2020; SILVA et al., 2020). A figura 5 apresenta a localização dos geomorfossítios no município de estudo. 
Figura 5: Locais de grande representatividade de relevo do tipo ruiniforme no município de Castelo do Piauí, Piauí, Brasil.

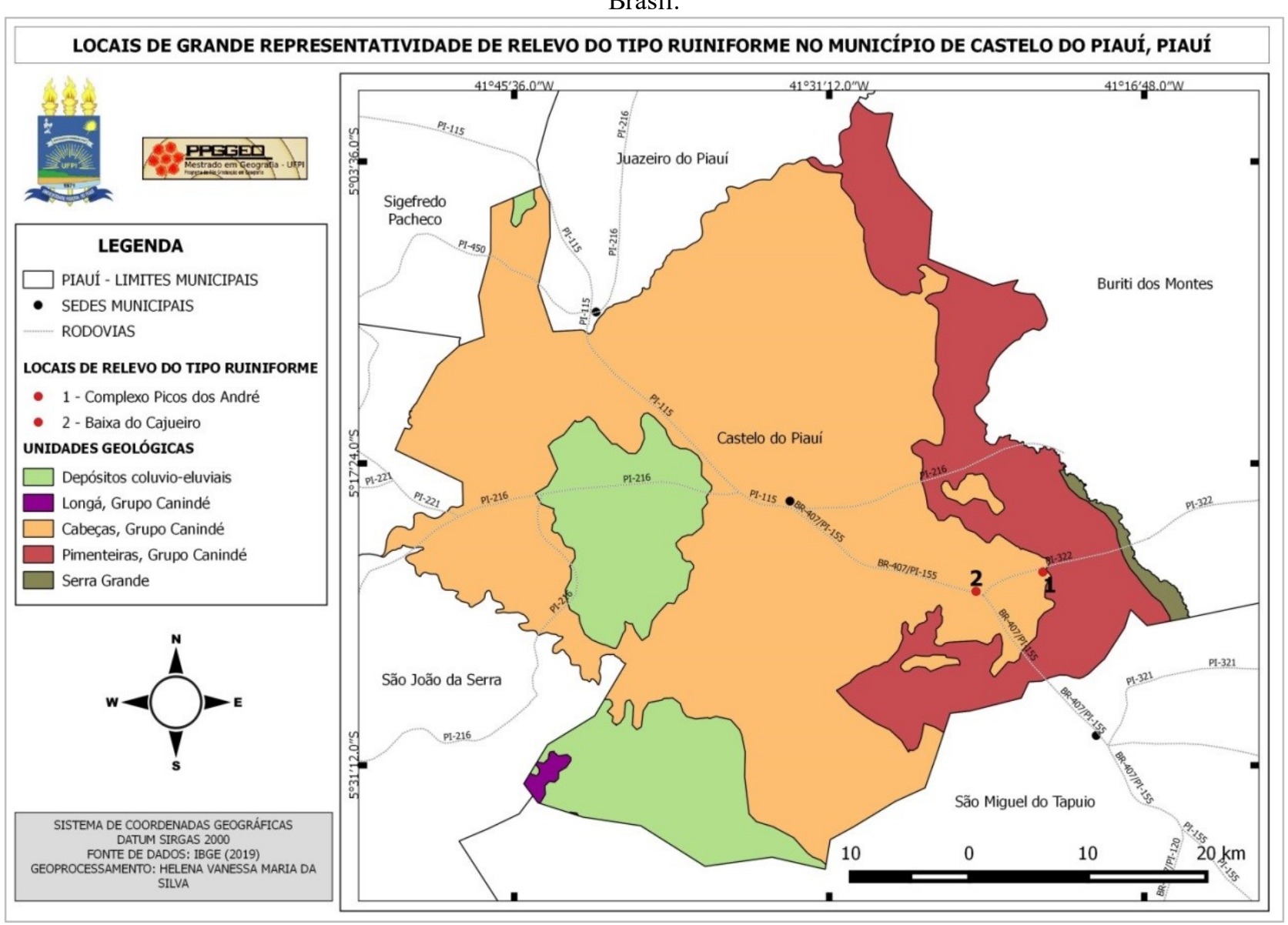

Organização dos autores, 2021.

\section{CARACTERIZAÇÃO: RELEVO RUINIFORME - GEOMORFOSSÍTIO BAIXA DO CAJUEIRO}

O geomorfossítio Baixa do Cajueiro localiza-se nas coordenadas $05^{\circ} 23^{\prime} 14.8^{\prime \prime}$ latitude sul e 041 $24 ’ 29.1^{\prime \prime}$ longitude oeste a 444 metros de altitude. O local é isolado e em propriedade privada, de acessibilidade moderada e boa visibilidade (Figura 6). 
Figura 6: Mirante Geomorfossítio Baixa do Cajueiro com superfície coberta por estruturas poligonais.

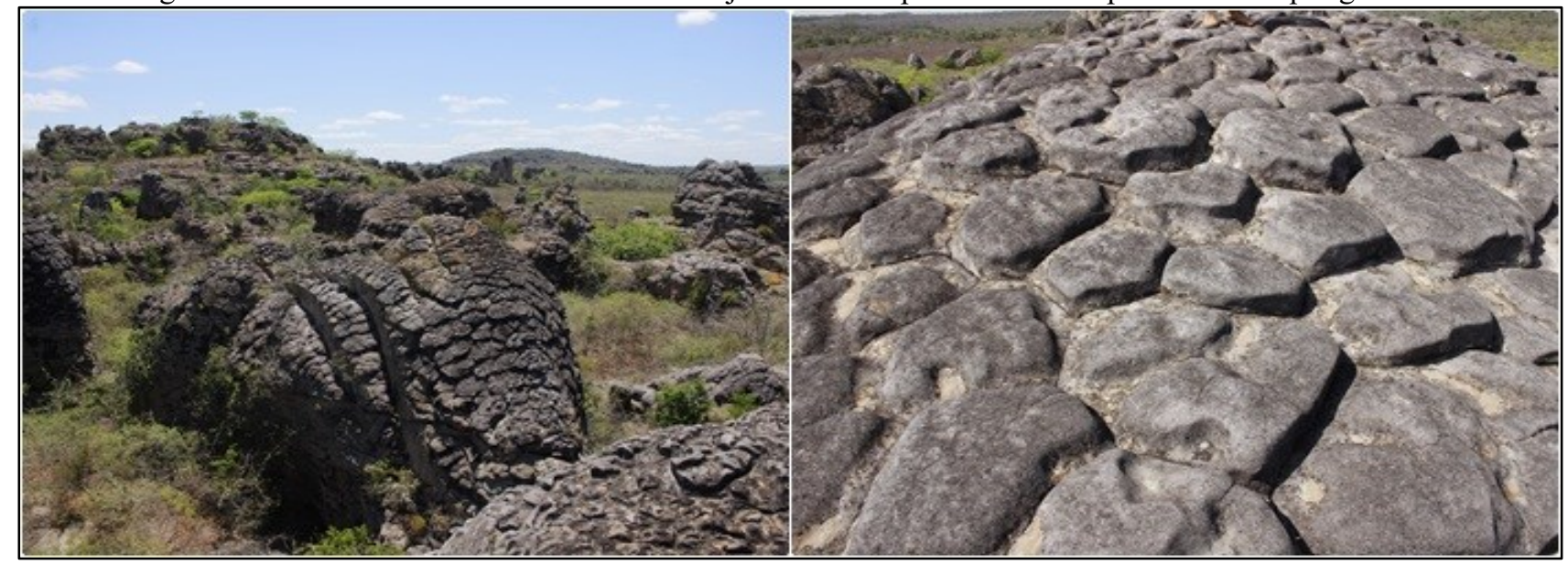

Fonte: Pesquisa direta, 2019.

Apresentando grande beleza cênica o referido geomorfossítio é divulgado, os valores científico, didático, cultural, turístico, ecológico, econômico e estético são assim elevados. Dentre os aspectos geológico/geomorfológicos a serem discutidos destacam-se temas relacionados a queda de blocos, falhas e fraturas, processos de intemperismo, de erosão diferencial em rochas areníticas (juntas poligonais).

No local é possível observar relevo do tipo ruiniforme com características geológicas relacionadas à Formação Cabeças, sendo constituída essencialmente de arenitos finos a médios, de coloração cinza e esbranquiçada, conglomerados em tons amarelados, siltitos e folhelhos de coloração avermelhada (Figura 7). 
Figura 7: Relevo do tipo ruiniforme, geomorfossítio Baixa do Cajueiro.

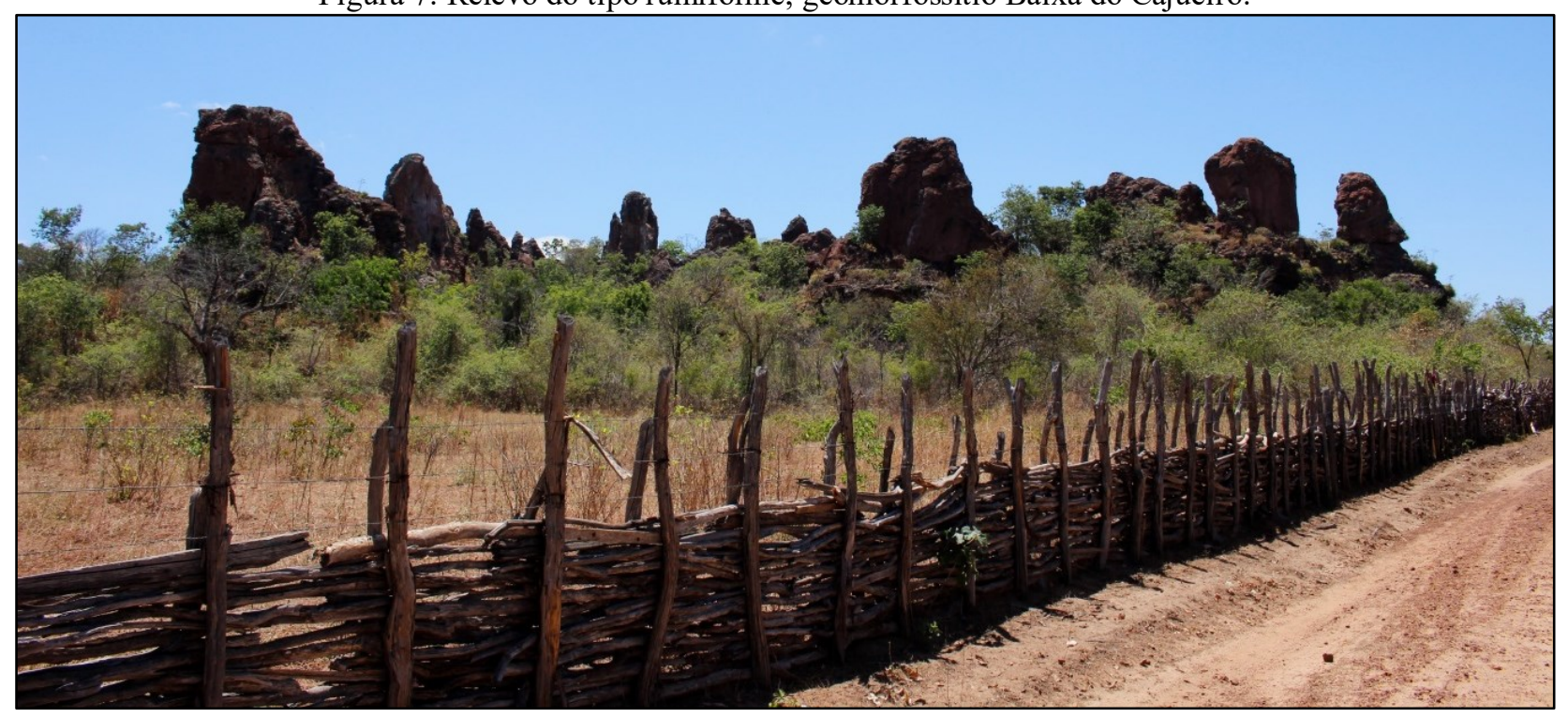

Fonte: Pesquisa direta, 2019.

Agregando valor cultural a este geomorfossítio no local ainda é possível visualizar inúmeras pinturas rupestres, o que permite a discussão sobre povos primitivos, evidências históricas (arqueológicas) na área (Figura 8).

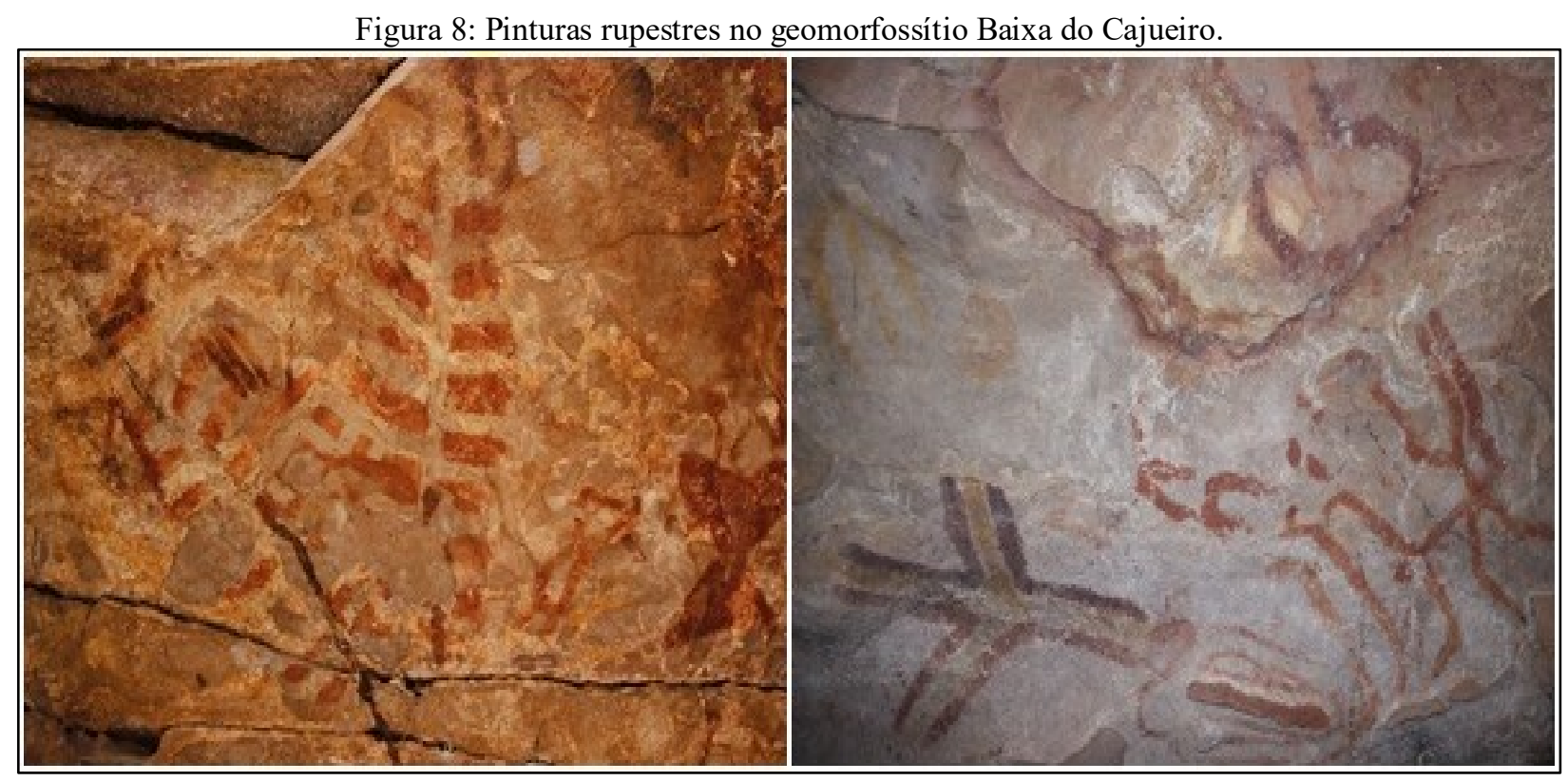

Fonte: Pesquisa direta, 2019.

Sem sinais de deterioração provocada por ação antrópica, apenas desgaste natural, o ambiente encontra-se em bom estado de conservação. Embora não haja nenhuma forma de proteção e gestão pelo poder público. 


\section{CARACTERIZAÇÃO: RELEVO RUINIFORME - GEOMORFOSSÍTIO PICO DOS ANDRÉ}

O geomorfossítio denominado de Complexo Pico dos André engloba diversas geoformas com os mais variados tamanhos e formatos, são formas de relevo ruiniforme elaboradas em arenitos da Formação Cabeças, que se destacam na paisagem, alguns em formato de pináculos ou picos, que justificam o nome dado ao geomorfossítio. Localiza-se nas coordenadas $05^{\circ} 22{ }^{\prime} 21.8$ " latitude sul e $041^{\circ} 21^{\prime} 25.7$ " apresenta altitude de 516 metros (Figura 9).

Figura 9: Geomorfossítio Complexo Pico dos André.

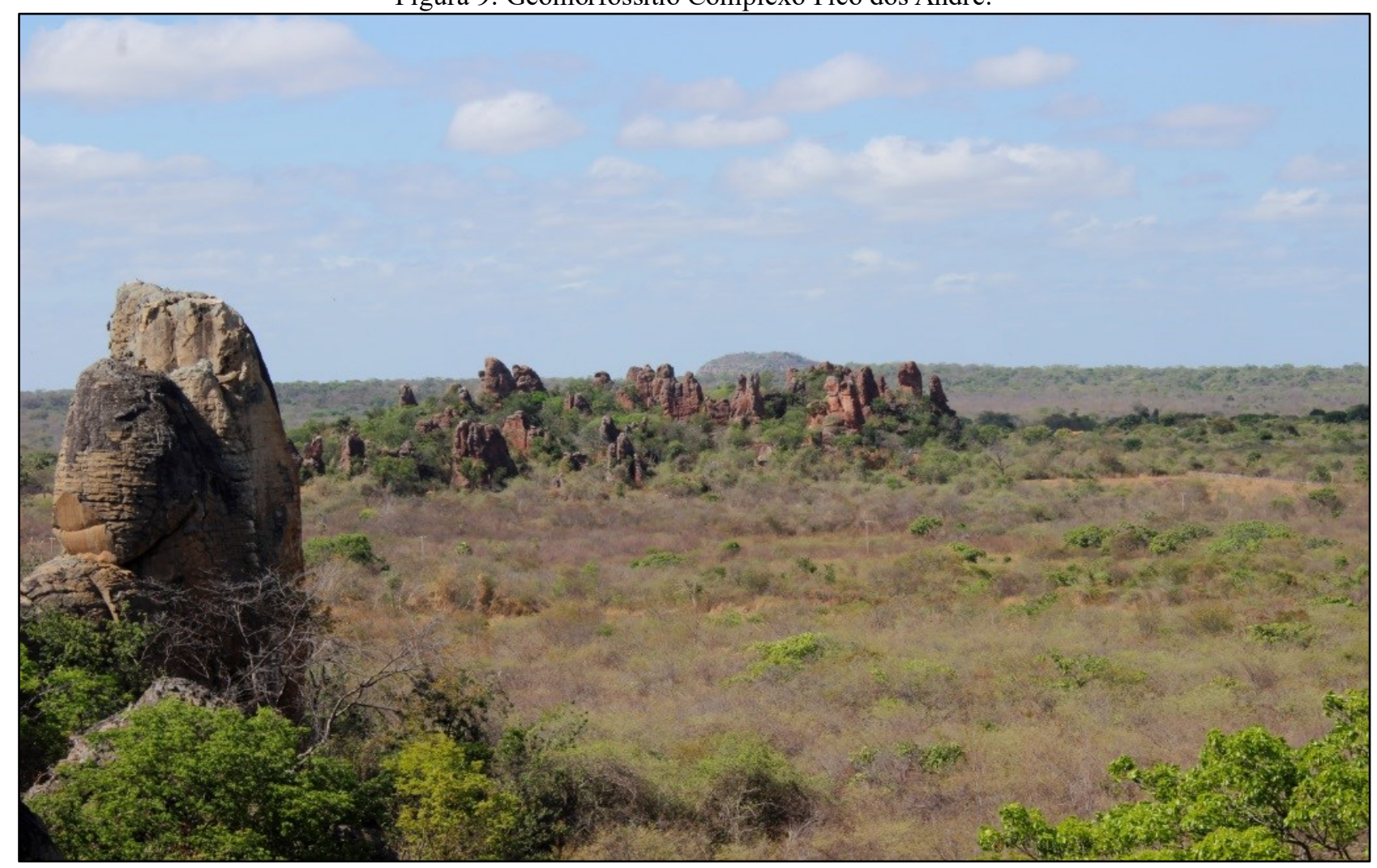

Fonte: Pesquisa direta, 2019.

Divulgado e usado como local de interesse paisagístico (lazer e turismo) o local é do tipo área representando geoformas de grandes dimensões ou conjuntos de geoformas. Está em propriedade privada, a acessibilidade é fácil e a visibilidade é boa. O Complexo Pico dos André apresenta valores científico, turístico, ecológico, cultural, estético e econômico elevados. As geoformas do mesmo são dotadas de rara beleza que impressionam aos visitantes (Figura 10). 
Figura 10: Detalhes do Geomorfossítio Complexo Pico dos André.
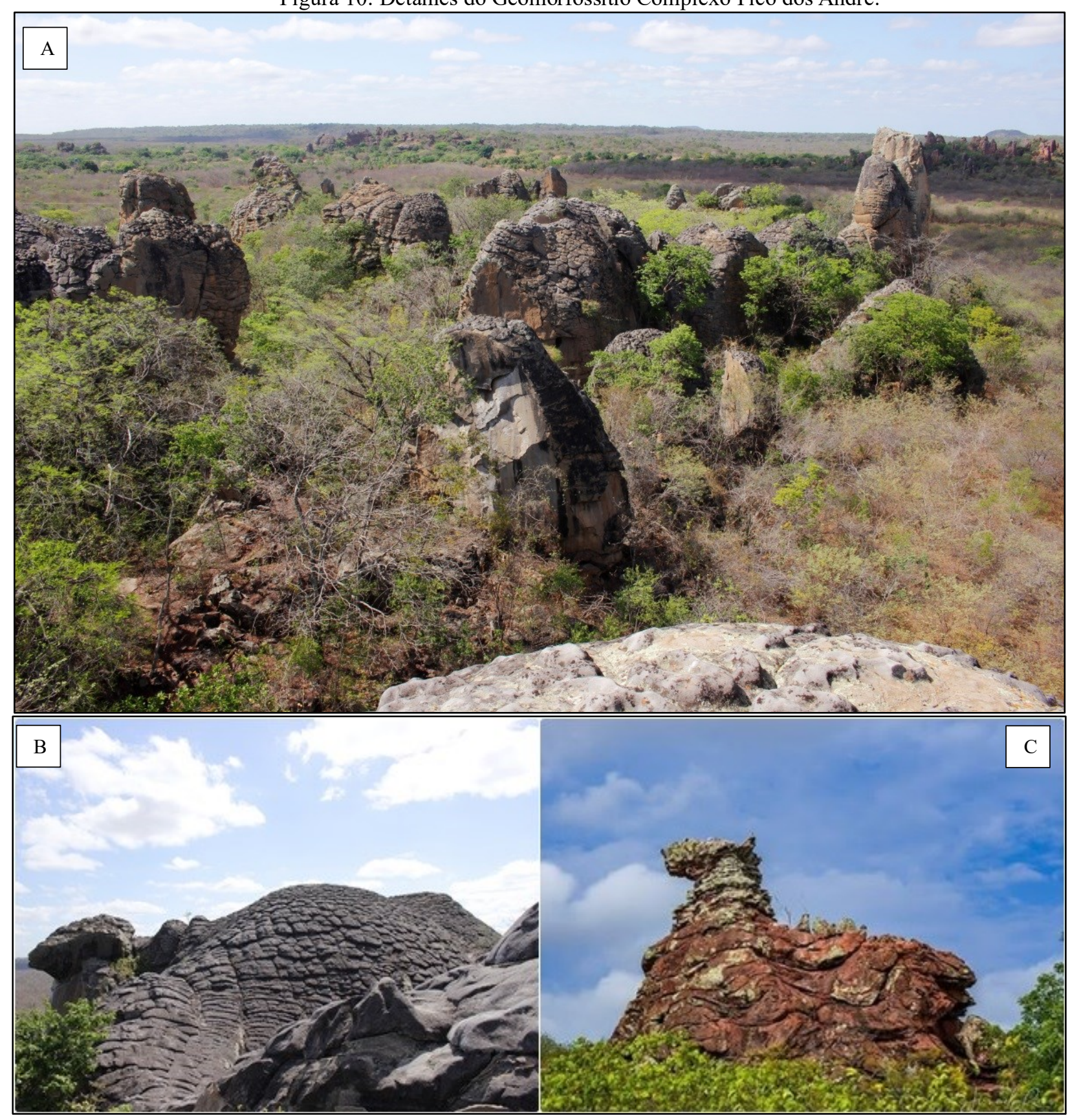

A - Complexo de pináculos (relevo em formato de picos); B - Geoforma Pedra da Tartaruga (uma geoforma erosional resultante de um sistema de fendas poligonais evidenciadas dada a ação do intemperismo); B - Geoforma Cavalo Marinho. Fonte: Pesquisa direta, 2019.

Ainda são visualizadas neste geomorfossítio inúmeras inscrições rupestres (pinturas e gravuras) no Sítio arqueológico denominado Ninho do Urubu (Figura 11). 
Figura 11: Abrigo Sítio arqueológico Ninho do Urubu, geomorfossítio Complexo Pico dos André, com destaque para pinturas e gravuras rupestres.

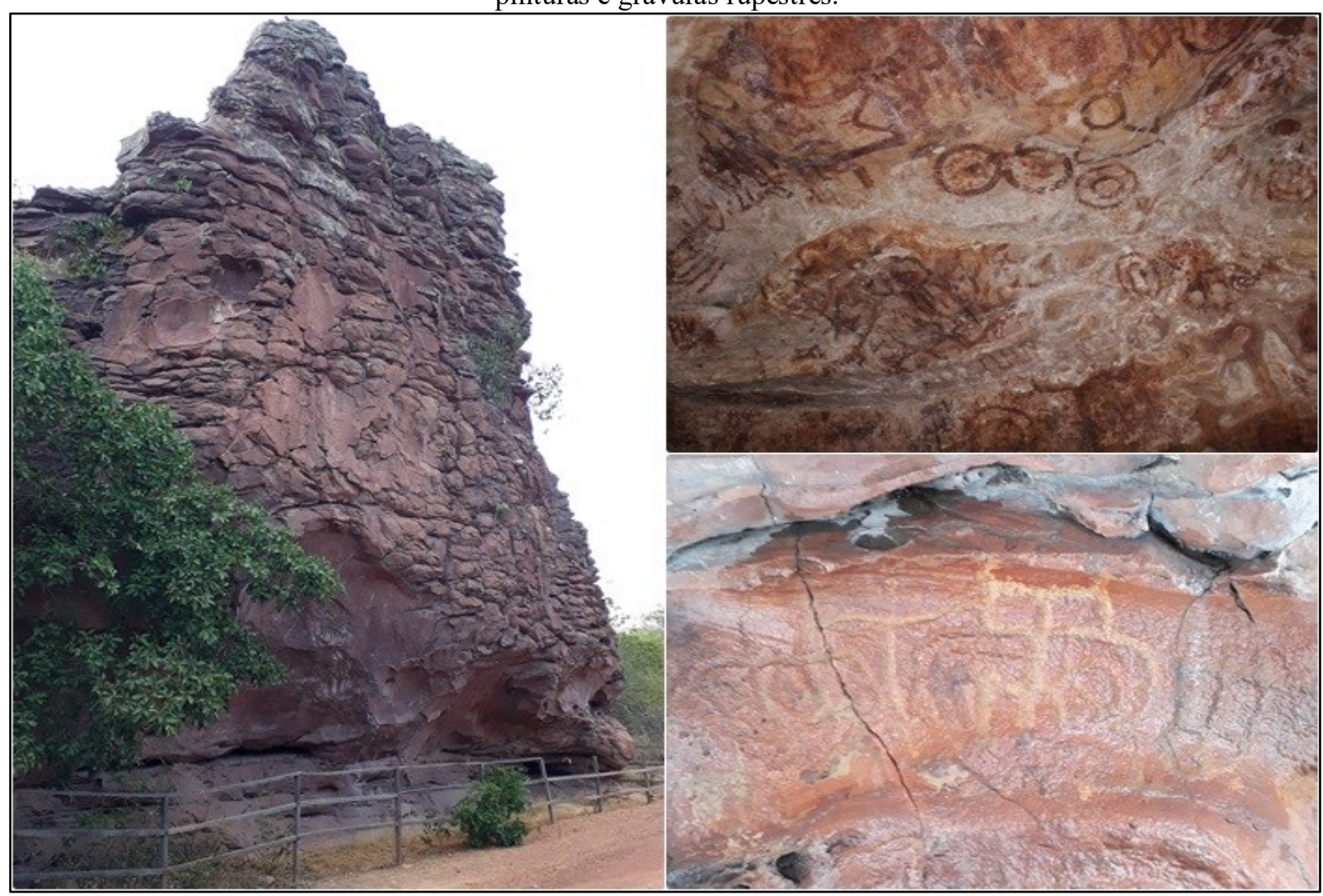

Fonte: Pesquisa direta, 2019.

Sobre a necessidade de proteção, a deterioração é fraca e a proteção moderada, assim como nos geomorfossítios anteriores as vulnerabilidades identificadas são apenas aquelas de ordem natural.

Considerando a inventariação realizada pode-se inferir o potencial da área de estudo para fins turísticos considerando os valores identificados (cênico, turístico, educativo, cultural) na área de estudo.

\section{CONSIDERAÇÕES FINAIS}

No município de Castelo do Piaú, o relevo ruiniforme é oriundo da erosão diferencial em arenito e apresentam-se como áreas com enorme potencialidade turística, devido o apelo de suas formas. Essa é a denominação atribuída nas ciências da terra, para paisagens com aspectos que lembram ruínas abandonadas. Neste estado, arenitos esculpidos por agentes eólicos, patrocinam uma grande variedade de relevos e paisagens desta natureza. 
Através da inventariação dos geomorfossítios Complexo Pico dos André e Baixa do Cajueiro (locais de grande espetacularidade de relevo do tipo ruiniforme) percebeu-se que suas características, potencialidade e valores associados (cênico, turístico, educativo, cultural), além da baixa vulnerabilidade do local constituem área potencial para o geoturismo.

Com vistas a perpetuar esses elementos, os conservar e fazer com que moradores e visitantes se sintam sensibilizados quanto a seus valores (científico, educativo/didático, turístico, entre outros), recomenda-se ao poder público municipal um planejamento turístico adequado que venha subsidiar ações, como a criação de roteiros, esquemas de interpretação do patrimônio natural e projetos de educação ambiental, dentre outros, como forma de fortalecer o geoturismo na região, e com isso dinamizar a economia do município.

Há também a necessidade de parcerias junto à comunidade local e instituições de ensino (escolas e universidades) a fim de criarem programas de visitação as áreas, devidamente programados e guiados, pensando em ganhos em termos de conservação, uma questão importante em se tratando do geoturismo.

A implantação do geoturismo em moldes sustentáveis deve ser pensado no sentido de permitir um desenvolvimento turístico sem danos aos recursos, de modo que os mesmos possam ser objeto de uso de nossa geração e das gerações futuras. É importante que o poder público dos municípios envolva a comunidade, criando programas de capacitação de guias e orientação acerca da vertente da natureza abiótica.

\section{AGRADECIMENTOS}

À Coordenação de Aperfeiçoamento Pessoal de Nível Superior (CAPES), ao Conselho Nacional de Desenvolvimento Científico e Tecnológico (CNPq), número do processo: 406587/20183 e a Fundação de Amparo a Pesquisa do Piauí (Fapepi) pela bolsa concedida (auxílio financeiro).

\section{REFERÊNCIAS}

AB'SABER, A. N. Topografia Ruiniformes no Brasil. In: Geomorfologia. São Paulo: Universidade de São Paulo, Instituto de Geografia, 1977.

AGUIAR, R.B.; GOMES, J.R.C. (Org.). Projeto cadastro de fontes de abastecimento por água subterrânea, estado do Piauí: diagnóstico do município de Castelo do Piauí. - Fortaleza: CPRM Serviço Geológico do Brasil, 2004. 
AQUINO, Cláudia Maria Sabóia de; AQUINO, Renê Pedro de. Geoturismo no município de Castelo do Piauí: Uma alternativa à geração de renda. Geoambiente on-line, v. 37, p. 202-215, 2020.

CUNHA, L.; VIEIRA, A. Geomorfologia, património e actividades de lazer em espaços de montanha, exemplos no Portugal Central. Colóquio Ibérico de Geografia, Huelva. [Online], 2002. Disponível em: http://www1.ci.uc.pt/cegc/pdfs/patrim.pdf.

GUERRA, A. T.; GUERRA, A. J. T. Novo Dicionário Geológico-Geomorfológico. Rio de Janeiro: Bertrand Brasil, 2006.

HARDT, R.; PINTO, S. A. F. Carste Em Rochas Não Carbonáticas. VIII Sinageo (anais CDRom). 11 p. 2009.

JACOMINE, P.K.T. Mapa exploratório-reconhecimento de solos do estado do Piauí. Convênio EMBRAPA/SNLCS-SUDENE-DRN. 1983.

LIMA, Jhony Gonçalves de. Avaliação do patrimônio geológico/geomorfológico do município de Castelo do Piauí - PI. 2020. Monografia (Graduação em Geografia) - Centro de Ciências Humanas e Letras. Universidade Federal do Piauí. Piauí, Teresina, 2020.

MORA FILHO, P.S.; RUAS, L.M.S. As contribuições da Geomorfologia ambiental no campo do turismo rural: a descrição paisagística como recurso metodológico para o planejamento turístico. Revista Saber Acadêmico, n.5, p. 40-49, 2008.

MELO, M. S.; BOSETTI, E. P.; GODOY, L. C.; PILATTI, F. Vila Velha, PR - Impressionante relevo ruineforme. In: SCHOBBENHAUS, C; CAMPOS, D. A; QUEIROS, E. T.; WINGE, M; BERBERTBORN, M.L.C. (Edits). Sítios Geológicos e Paleobiológicos do Brasil. 1 Ed. Brasilia: DNPM/CPRM - Comissão Brasileira de Sítios Geológicos e Paleobiológicos (SIGEP), 2002, v.01: 269-277.

MEIRA, S. A.; SANTOS, G. B. Relevo ruiniforme da Serra dos Tapuias - Bahia: Características e potencialidades. REVISTA GEONORTE, Edição Especial 4, V.10, N.1, p.665-669, 2014.

OLIVEIRA, P. C. A. Avaliação do patrimônio geomorfológico potencial dos municípios de Coromandel e Vazante, MG. Uberlândia, 2015. Tese (Doutorado em Ciências Humanas) Universidade Federal de Uberlândia, Minas Gerais, 2015.

SILVA, J. F. A. Geodiversidade e patrimônio geológico / geomorfológico das "Cidades de Pedras" - Piauí: potencial turístico e didático. 2017. Dissertação (Mestrado em Geografia) - Universidade Federal do Piauí. Teresina, 2017.

SILVA, Helena Vanessa Maria da. Geodiversidade e geopatrimônio dos municípios de Juazeiro do Piauí, Novo Santo Antônio, São João da Serra e Sigefredo Pacheco, Piauí. 2020. Dissertação (Mestrado em Geografia) - Centro de Ciências Humanas e Letras. Universidade Federal do Piauí. Piauí, Teresina, 2020.

SILVA, Helena Vanessa Maria da; LIMA, Jhony Gonçalves de; AQUINO, Claudia Maria Sabóia de; AQUINO, Renê Pedro de. Potencial turístico e didático de geomorfossítios no município de Castelo do Piauí- PI. In: FALCÃO SOBRINHO, José; NASCIMENTO, Flávio Rodrigues; CLAUDINOSALES, Vanda de. (Org.). Geodiversidade: abordagens teóricas e práticas. 1ed.Sobral/Ceará: Sertão Cult, 2020, v. 6, p. 145-171.

SUGUIU, Kenitiro. Dicionário de geologia sedimentar e áreas afins. Rio de Janeiro: Bertrand Brasil, 1998. 1.222p. 